\title{
Llueve sobre mojado. El Conurbano Bonaerense entre nuevos \\ y viejos confinamientos
}

\section{Daniela Soldano y Noelia Villarroel}

\author{
Daniela Soldano es docente e investigadora de la Universidad Nacional del Litoral, Argentina \\ E-mail: da.soldano@gmail.com
}

Noelia Villarroel es docente e investigadora de la Universidad Nacional de José C. Paz, Argentina. E-mail: noelia1305@hotmail.com

El hecho de que la desigualdad social es la marca dominante de la cuestión social en la Argentina es un dato ya confirmado por la sociología y la cultura. La existencia de núcleos de exclusión social severa-enquistados territorialmente y en frágil relación con la sociedad "integrada"- constituye, desde hace décadas, una realidad impermeable a las intenciones de las políticas sociales y urbanas.

Los últimos meses permiten contemplar la cadencia de esa desigualdad. Territorios que parecen imbricarse en un orden social y urbano más amplio en tiempos de relativa bonanza ven encenderse los bordes de aquello que los separa cuando las variables de contexto cambian como hoy.

El confinamiento sanitario en los barrios relegados del Gran Buenos Aires debe entenderse a contraluz de esta realidad, y sobre las experiencias de otros confinamientos del pasado.

Hace casi dos décadas, la crisis económica de 2001 imponía un proceso de repliegue brutal a las familias pobres del conurbano. Esas jornadas trágicas demostraron que la pobreza podía sobrepasar el umbral conocido de las privaciones cotidianas y de la incertidumbre de vivir al día. El fin de la convertibilidad puso el factor territorial de la desigualdad social y económica en un rutilante primer plano.

Las barriadas históricamente relegadas vivieron, en esos días aciagos, un proceso de "cercado" de sus espacios, los cuales se constituyeron en reservorios cruciales para la reproducción de la vida. La falta de dinero les impedía a los residentes salir de los barrios, pero además, una frontera simbólica -que llegó para quedarse en el imaginario ciudadano- fue esmerilando las expectativas de movilidad social y urbana para estas familias. ¿Salir? ¿A qué?

Muy poca gente tenía teléfono celular y, si contaba con uno, no podía comprar tarjetas precargadas. Los trabajadores de la construcción perdían las conexiones con los capataces. A las empleadas domésticas se les hacía difícil sostener el feaxture de trabajo por horas. Los vendedores ambulantes no podían comprar mercadería y en el tren no se vendía nada.

Sobrevivir en el mundo sin dinero de las periferias del Gran Buenos Aires impulsó el desarrollo de nuevos intercambios y una actualización de saberes aprendidos en el pasado. En efecto, muchas de las familias que armaron los clubes de 
trueque y se animaron a montar sus puestitos en las ferias populares de la crisis habían participado en las ollas populares de 1989, cuando en la Provincia de Buenos Aires la hiperinflación hizo estallar la cuestión social en mil pedazos.

Además, hacia el año 2001, el Estado había aprendido a desarrollar políticas sociales "de enclave", para mitigar el hambre y la miseria en estos territorios. Una lluvia de programas asistenciales -alimentarios, sanitarios, de empleo, de mejoramiento barrial- intersectaba fragmentariamente las necesidades de las familias, inyectando recursos que se articularon con efectividad relativa en sus repertorios. Siempre ineficientes, siempre vitales, esos programas modelaron sus vidas, sus desplazamientos, sus sociabilidades y su subjetividad. También -es muy importante decirlo- fueron modeladas por la mirada de la sociedad en su conjunto, que desde entonces y hasta el presente desconfía de la veracidad de los estados de necesidad y cree reconocer estrategias racionales y acumuladoras en las experiencias de recepción.

En algunos de los que en su momento llamamos "barrios bajo planes", se desarrolló un denso mundo asociativo al calor de los requerimientos del Estado. Asimismo, huelga decir, los municipios densificaron el poder de sus redes clientelares. En efecto, fueron estos los tiempos del crecimiento exponencial de la capacidad de mediación y provisión de las organizaciones sociales, así como del reinado de la discrecionalidad. Con independencia de que los planes estatales estipularan los criterios de entrega de los recursos, permitían cierto juego, cierta maniobra, a veces hasta "justa" en un mundo de tan intensas necesidades, a veces, a todas luces "inmoral" y facciosa. Mientras tanto, las instituciones estatales - centros de salud, jardines de infantes, escuelas- contenían a la ciudadanía periférica con lo que podían: magros recursos y retóricas basadas en la necesidad y en merecimientos.

La recuperación económica del segundo lustro de la década de 2000 permitió la mejora en los ingresos de las familias que viven de ocupaciones informales. Sus consumos usualmente se expandieron en el mar de créditos leoninos -"a sola firma"- que solían ahogarlos en circuitos de cuotas eternas y usureras. El Estado siguió ahí, acompañando sus clásicas intervenciones asistenciales y sus servicios sociales y urbanos expoliados con la novedad de transferencias de dinero condicionadas al cumplimiento de compromisos que sin duda trajeron alivio, pero que no removieron posiciones desiguales ni despejaron la incertidumbre.

\section{La desigualdad al ras de la vida social}

La prueba más evidente de esas desigualdades sociales y urbanas persistentes ha quedado expuesta como una herida abierta en estos meses de pandemia. Si miramos al ras de la vida social, es posible comprender cuál es el estado de las relaciones sociales y de los intercambios realmente existentes entre distintos sectores sociales. Se trata de relaciones que hacen al núcleo de la producción de la desigualdad. Proponemos mirar estas dinámicas desde una breve descripción de la realidad cotidiana de los habitantes de uno de estos lugares del Gran Buenos Aires, como es el caso de Sol y Verde, en el partido de José C. Paz. 
La mayoría de las trabajadoras domésticas no han percibido sus ingresos desde Marzo. Los argumentos de los empleadores han sido varios: desde "no puedo abrir el negocio" y "no tengo ingresos para pagarte" hasta el silencio más absoluto. A esto se suma que muchas de ellas no han podido aplicar al Ingreso Familiar de Emergencia (IFE) porque sus parejas -o sus ex parejas, de quienes no se han divorciado- se encuentran con trabajos registrados. A la conocida y desigual gestión solitaria del cuidado de los hijos se sumó la calamidad de la violencia económica que supone no recibir la cuota alimentaria parental por argumentos similares a los esgrimidos por los empleadores. No hay trabajo: no hay dinero.

Las mujeres y las familias, sin embargo, saben sobrevivir, tienen una vasta experiencia en lidiar con las restricciones: conviven con otros, elaboran muchos más alimentos en forma casera - pastas y panificados-y comparten las tareas domésticas y de cuidado, así como los gastos de la alimentación y de servicios básicos.

Adicionalmente, el efecto del aislamiento en condiciones de pobreza grave es subjetivamente demoledor. No solo se trata de un corte brutal de sus ingresos, sino también significa un cambio total de sus rutinas. Las mujeres nos cuentan que volvieron a los malabares con la gestión del plato de comida, a enfrentar el tsunami de las tareas escolares de los hijos y a encarar la cuesta de los tratamientos de salud crónicos. Se suspendieron los controles médicos programados y los espacios terapéuticos de fonoaudiología y psicopedagogía, lo que ha generado preocupación por los retrocesos en campos bien sensibles del desarrollo de la infancia.

La angustia derivada del encierro se paga con sufrimiento corporal y psíquico. Nos cuentan que han perdido todo su tiempo personal. En sus casas muy precarias, prima la indiferenciación de espacios. Sobre una misma mesa, hay que resolver tareas, amasar, pasar el tiempo de la vida.

Los trabajadores de la construcción se encuentran en una situación similar. Sin trabajo, no hay paga. A algunos de los que están registrados -y que por esta razón ni ellos ni sus parejas pueden acceder al IFE- se les ofreció un adelanto de 10.000 pesos que deberán devolver cuando se reactive la actividad. Los trabajadores independientes, es decir, los que se dedican a la venta ambulante y a las changas, no tienen trabajo. Desde hace bastante tiempo ya, los pequeños emprendedores no entregan productos o servicios sin el pago adelantado o una seña. Entonces, este circuito de generación de ingresos está casi desactivado. Quienes se dedican al cartoneo se enfrentaron a la incertidumbre de la cuarentena en un contexto de reglas de juego inciertas. Las primeras semanas, la actividad estaba restringida, sobre todo la circulación por las zonas de centralidad del municipio donde se pueden obtener objetos y materiales para reciclar. Además, por primera vez en casi dos décadas de existencia, la feria cartonera de Sol y Verde no abrió. La más popular del noroeste del Conurbano se "acuarentenó".

"La cartonera" es (¿fue?) el solar donde se estacionaban los carros que bajaban del servicio del Tren San Martín con la ropa, zapatos, electrodomésticos, viejos souvenirs, juguetes, vajilla y enceres usados recolectados en los barrios de la Ciudad de Buenos Aires. Eran objetos que adquirían un valor "renovado" en un territorio periférico e insularizado. La feria era un collage de mantas sobre la tierra 
y puestos con estructura donde también se vendían mercaderías y ropa nueva, además de comida, y donde los vecinos se juntaban todos los fines de semana a departir, intercambiar y esparcirse.

Este es un territorio de reglas inciertas, de mensajes estatales equívocos. Si bien está vigente la prohibición de desplazarse sin permisos fuera del ámbito de proximidad de la vivienda, los vecinos toman trasporte público con la normalidad habitual. Es que en los barrios no existen ni bancos, ni cajeros automáticos, ni locales de "Pago Fácil" o "Rapipago", por lo que, para pagar los servicios e impuestos y para extraer sus magras reservas de efectivo, es necesario movilizarse hasta el centro de José C. Paz.

Tener billetes es especialmente importante para poder comprar garrafas y mercaderías en alguno de los dos supermercados chinos que no aceptan pago con tarjetas y que, además, tienen un rango horario más amplio. Los pequeños almacenes con posnet en los que se pueden utilizar la tarjeta Alimentar, Más Vida o Ticket Nación están abiertos hasta las 14 o hasta las 19hs. Buena parte de los comercios restringen la venta de algunos productos de la canasta alimentaria básica -harina, fideos, aceite, puré de tomate- a una unidad por grupo familiar. Hay faltantes de productos de limpieza e higiene.

El cierre temprano de los comercios ha transformado el paisaje del barrio, acostumbrado a empezar a moverse febrilmente al atardecer, cuando solían regresar mujeres y hombres de sus jornadas de trabajo en la Ciudad de Buenos Aires. A partir de las $19 \mathrm{hs}$ y hasta las $22 \mathrm{hs}$, la policía bonaerense y la patrulla urbana recorren las calles.

Pasan solo dos vendedores ambulantes. Uno con pan casero y "churretes" -una mezcla de churros, bola de fraile y rosquitas-y el que vende copos de nieve. En el barrio no hay delivery. La parrilla cerró y solo funciona una pizzería. Aquí nunca funcionaron las aplicaciones de venta de alimentos y otros productos tales como "Pedidos ya", "Glovo" o "Rappi". El único comercio que desde el centro de José C. Paz comenzó a realizar algunas entregas a domicilio es la heladería de la cadena Grido. Sin embargo, pocos piden, según señalan.

Los efectores estatales han cerrado hasta nuevo aviso o han bajado la intensidad de su presencia. Luego de entregar los alimentos al comienzo de la cuarentena, según los envíos desde el Consejo Escolar, las dos escuelas públicas cancelaron toda actividad en la institución y la relación presencial con las familias. Las actividades pedagógicas se organizaron a través de unos cuadernillos y de Facebook. La escuela privada de la zona, en cambio, organizó las actividades virtuales a través del correo electrónico. Con el fin de percibir las cuotas la administración de dicho establecimiento, definió un horario reducido de atención al público donde acepta el pago exclusivamente en efectivo. También se acepta transferencia bancaria, pero, como ya dijimos, la mayoría de las familias aquí no utiliza medios de pago electrónicos y no tiene su economía bancarizada.

Los servicios de salud de proximidad iniciaron este período en una situación de desabastecimiento crónica. El Centro de Atención Primara continúa abierto solamente hasta las $19 \mathrm{hs}$. Atiende una guardia médica mínima, sin vacunatorio, y 
otorga turnos de las especialidades como ginecología, pediatría y clínica, pero sin efectivizar la atención. Los vecinos comentan que los turnos se suspenden sistemáticamente. El deterioro de la infraestructura exterior también es notable: es un centro en situación de abandono.

A diferencia de otros barrios del municipio, como Vucetich, Primavera o Frino, Sol y Verde no cuenta con una trama de organizaciones sociales lo suficientemente fuerte como para funcionar en términos de red de asistencia y contención. En este momento, no hay comedores ni merenderos ni instituciones que entreguen comida preparada con regularidad. Por su parte, desde el nivel municipal no se reforzaron estrategias de asistencia alimentaria, y el intendente solo ha dicho que quien la pida será visitado por una "asistente social".

Hasta diciembre de 2019, funcionó el programa "El Estado en tu barrio". En Frino tenía un punto fijo, y en la estación de Sol y Verde solía estar una vez al mes. Ahí se podía gestionar el D.N.I., el Plan Más Vida y trámites de Anses, lo cual facibilitaba enormemente el acceso a estos servicios. A diferencia de otros distritos como La Matanza, donde existen trailers de renovación de D.N.I., en José C. Paz no funciona el registro civil.

En este contexto, las viejas manzaneras del Plan Vida, creado por Chiche Duhalde en 1996, siguen siendo un actor social estratégico, que facilita y agiliza la obtención de la asistencia. Más allá de no desempeñar un rol de mediación específico -en el presente, el plan Mas Vida es una tarjeta de compra-, son el nexo entre las familias y el área de desarrollo social municipal. Los vecinos siguen percibiéndolas como las "ventanillas del Estado" en el barrio. Las consultan para todo, y ahora lo hacen por el Ingreso Familiar de Emergencia y la tarjeta alimentaria.

\section{¿Infraciudadanías? La relegación como forma de integración}

Las personas que hoy lidian con el nuevo aislamiento saben capear el temporal. Así como la marginalidad y la informalidad son sus formas de incorporación al mercado de trabajo en sociedades con economías heterogéneas y periféricas como la nuestra, la relegación social y urbana es la manera en la que estos ciudadanos se integran a la vida de la ciudad y de la sociedad. No se trata de una anomalía, de una condición transitoria, sino de un modo de incorporación estructural: subordinada y estigmatizante.

Más allá de momentos en los que la mejora relativa de la actividad económica les permite ampliar sus canastas de consumo y activar sus aspiraciones, la marca dominante de la vida de esta condición ciudadana es la de la continuidad de la desprovisión de servicios, los malos trabajos, los bajos ingresos y el déficit habitacional y urbano. Por ello, la consigna "quedate en casa” genera aquí un eco extraño. Esto no es una aldea. La vida cotidiana es refractaria al cobijo y a la tranquilidad de lo próximo. Si las rutinas metropolitanas están hechas de desplazamientos en procura del trabajo, del ingreso y de consumos, desde los bordes esta agenda se agudiza, y el aislamiento es sinónimo de pérdida.

Veinte años después de 2001, el barrio sigue siendo tanto reserva de sobrevivencia como enclave. Los lazos con el afuera continúan blandiendo su fragilidad. 
El Estado, por su parte, "planea" sobre el encierro, lanza mensajes esquivos y soluciones temporales e insuficientes, todo lo cual les recuerda a los ciudadanos el lugar que -con independencia de la retórica de derechos y de las intenciones comunitariamente solidarias-efectivamente ocupan.

Mayo de 2020

Daniela Soldano y Noelia Villarroel, "Llueve sobre mojado. El Conurbano Bonaerense entre nuevos y viejos confinamientos". Revista Temas y Debates. ISSN 1666-0714, año 24, número especial, juliodiciembre 2020, pp. 35-40. 